\title{
A Research Paper on Fabrication of Power Generation by Using Railway Track
}

\author{
Prof. S.S.Pawar ${ }^{1}$, Rushikesh B. Aher ${ }^{2}$, Yogendrakumar S. Kapse ${ }^{3}$, Ashvin S. Meshram ${ }^{4}$ \\ ${ }^{1}$ Assistant Professor, Smt. Radhikatai Pandav College of Engineering, Nagpur, India-441203 \\ ${ }^{2,3,4}$ UG Students, Smt. Radhikatai Pandav College of Engineering, Nagpur, India-441203
}

Received on: 20 May,2021,

Revised on: 24 June,2021,

Published on: 26 June,2021

\begin{abstract}
An idea to produce electricity from train track, the project is proceeded with the help of Rack and Pinion mechanism. The rotational force from Rack and Pinion mechanism is propagated into the chain drive and through the generator. Whenever the train is allowed to pass over the train track with beam setup, it gets pressed downwards. As the helical springs are attached to the setup, they get compressed and the rack, which is attached to the bottom of the setup, moves down in reciprocating motion. Since rack has teeth connected to pinion there is conversion of reciprocating motion of rack in to rotary motion of pinion, but the two gears rotate in opposite direction. So that shafts will rotate with certain RPM these shafts are connected to a sprocket and chain arrangement, which converts the mechanical energy into electrical energy. The chain arrangement with small sprocket at the end is coupled with the $12 v$ dc dynamo. Finally, the power produced from the dynamo is sent to the LED light.
\end{abstract}

Keywords- Sustainable, Conventional, NonConventional, Rack and Pinion, Dynamometer.

\section{I- INTRODUCTION}

W orld is growing at the faster rate with regards to consumption of fuel and so the scarcity of energy as the sources producing them are depletable in nature. Around the world, there were 8,06,000 cars and light trucks on the road consuming 260 billion US gallons 980000 liters of gasoline yearly. Railways were first introduced to India in 1853. By 1947, the year of India's independence, there were forty-two rail systems. In 1951 the systems were nationalized as one unit, becoming one of the largest networks in the world. IR operates both long distance and suburban rail systems. Indian railways operate about 9000 passenger trains and transports 17 million passengers daily across twenty-eight states and three union territories. IR owned about 225,000 wagons, 45,000 coaches and 8300 locomotives and ran more than 18,000 trains daily. We are looking forward to conserve the kinetic energy that gone wasted, while trains move. The number of trains passing over the system fixed on the railway track is increasing day by day.

1. We proposed a non-conventional power generating system based on railway track mechanism which generates electricity without using any commercial fossil fuels, which is not producing any polluting products. In this paper, our aim is to conserve the kinetic energy which convert into electricity that gone wasted, while train move on track.

2. Unfortunately, a substantial portion of railroad tracks exist in remote areas or certain underground regions in which there is little electrical infrastructure. In these regions, instalment of equipment such as warning signal lights, wireless sensors for railway track monitoring, bridge monitoring and train positioning have limited practical deployment due to the lack of a reliable power supply or low 


\section{International Journal of Innovations in Engineering and Science, www.ijies.net}

maintenance battery. Therefore, it is necessary to design a cost-effective and reliable power supply to track-side sensors and equipment.

3. This project work includes simple rack and pinion arrangement with increased gear ratio which then moves a dynamometer to generate the electricity. The generated power can be stored into the battery and used to power track side equipment's. Railroad energy harvesting is no trivial disturbance. In our project we are using these powers for irrigation system to the nearby lands and fields and for lamp lights near the track.

\section{II- OBJECTIVES}

The main objective is to build a power generation system such that it can contribute to the present power generation system as the need of energy is growing day by day. The generated power is ecofriendly as well as inexhaustible means the power can be generated as long as the railways are in function. This can be achieved by utilizing the energy resources along the railway tracks i.e., by utilizing the mechanical energy supplied by both wind gust from train as well as mechanical energy supplied by the train when it is in motion. The proposed technique relates generally to generating electricity and, more particularly, to a method and a system for generating electricity along a railroad track. Many known railroad systems employ a variety of wayside equipment alongside the railroad tracks. Within a network, railroad tracks often span rural and unpopulated areas, and as such, providing power to wayside equipment in remote locations may be a challenging and costly task. At least some known railroad systems run power lines into remote areas to power wayside equipment. However, depending on the location, such power systems may be expensive to install and to maintain.

\section{III - COMPONENTS}

From our survey we identified the suitable material for all the above parts. Such mechanism is to be mounted on frame. The entire frame such as Railway track, supports, C Channel is made from mild steel. All the assembly is done through welding

\section{- STEEL FRAME}

It is constructed from mild steel and by applying MIG welding. The frame dimensions are such that it can incorporate a rack and pinion arrangement as well as two shaft and a spur gear pinion arrangement. The dynamometer is used to produce the electricity.

\section{- HELICAL SPRING}

A spring is an elastic body whose function is to distort when loaded and to recover its original shape when the load is removed. It cushions, absorbs or controls energy either due to shocks or due to vibrations.

\section{- RACK AND PINION}

Rack and pinion can convert rotary to linear of from linear to rotary motion. Rack is a linear gear and pinion is a circular gear. Applied force on rack is converted to rotation by pinion. The mechanical force is converted into rotational force.

\section{- SHAFT}

A shaft is a rotating machine element, usually circular in cross section, which is used to transmit power from one part to another, or from a machine which produces power to a machine which absorbs power. The various members such as gears are mounted on it. In our project we use two shafts one is connected with dynamo and another one is connected with rack and pinion arrangement.

\section{- BEARING}

A bearing is a machine element that constrains relative motion to only the desired motion, reduces friction between moving parts.

\section{- SPUR GEAR AND PINION}

It is rotating disc type structure having several teeth cuts on it. Here two gears are used made from Cast Iron. Big gear is mounted on main shaft and other pinion is mounted on counter shaft which continuously meshes.

\section{- DYNAMOMETER}

The device which converts mechanical energy into electrical energy is called generator. An AC generator is used for producing alternating current which contains an assembly of stationary (stator) and moving parts (rotor). The rotor is connected with the gear. The torque which generated by gear rotates the rotor of the generator. The rotor creates a moving magnetic field around the stator, which induces a voltage difference between windings of stator and produce the alternating current (AC) output of the generator.

\section{IV- POWER CALCULATION}

While implementing,

Load applied by one wheel of the train is 8.125 tons on a load train.

Finally, the load on the beam is $\mathbf{1 6 . 2 5}$ tons.

Height of the beam track fitted $15 \mathrm{~cm}$.

Weight of the body $=16250 \times 9.81=159412.5 \mathrm{~N}$

Distance $=\mathbf{1 5} \mathbf{c m}$. 


\section{International Journal of Innovations in Engineering and Science, www.ijies.net}

Power $=$ work done $/$ second $=(159412.5 \times 0.15) / 60=$ 398.53

While implementing our project approximately we get $398.53 \mathrm{v}$ of power. Since our project is just a model, we get very less power.

Our project, Load is applied manually $5-10 \mathrm{~kg}$.

Height of the beam fitted $2 \mathrm{~cm}$.

Since manual load weight is same as applied load $1 \mathrm{~kg}$ (approx.)

Weight of the body $=10 \times 9.81=\mathbf{9 8 . 1} \mathbf{~ N}$

Distance $=\mathbf{2} \mathbf{c m}$.

Power $=(98.1 \times .02) / 60=\mathbf{0 . 3 2 7} \mathbf{W}$.

However, power generation from the project is very less but it will not create any pollution and environmental hazards. Our project is a purely eco-friendly one and with the help of our project it is possible to green energy.

\section{V- BLOCK DIAGRAM}

In our project, we create a model of train track, in that we fit a beam track arrangement and followed to that rack and pinion arrangement and chain drive. Finally, it is connected to the dynamo to LED.

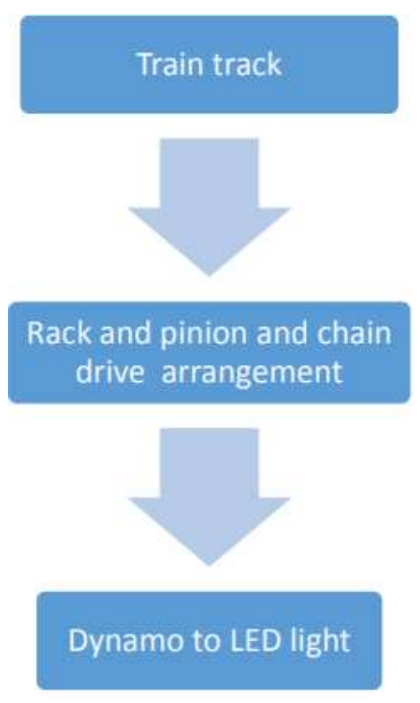

\section{VI - WORKING}

This project explains the mechanism of electricity generation from train track. The load acted upon the beam in train track by train wheel is transmitted to rack and pinion arrangement. Then, reciprocating motion of the beam track arrangement is converted into rotary motion using the rack and pinion arrangement where the axis of the pinion is coupled with the sprocket arrangement. This project explains the mechanism of electricity generation from train track. The load acted upon the beam in train track by train wheel is transmitted to rack and pinion arrangement. Then, reciprocating motion of the beam track arrangement is converted into rotary motion using the rack and pinion arrangement where the axis of the pinion is coupled with the sprocket arrangement

\section{VII - RESULTS}

In the first test of our project there is some lag due to irregular arrangement of rack and pinion gear. After rectifying that, chain drive make some problems and our team remove the chain fix that issue. After that our project run well and gives certain desired outputs. Finally, we make several tests and calculate the power produced and we connect with LED to check that the output is enough or not. After a long time, we complete our entire work and also project works well.

\section{VIII - SAFETY ISSUE}

Safety is essential one while doing projects; in our project we generate power from railway track. While doing these kinds of projects safety is an important one. Many of them bother that it will create some kind accident and some other issue. It will not create any damage to the train and also to the passengers. Because we use just a helical spring it is easy to compress so the train need not to pull a heavy load and also 16 ton train compartment is not affected by pulling down the small load.

\section{IX - CONCLUSION}

This, generated electricity can be stored in batteries and can be used for various purposes for example illuminating street lights. Now, train traffic is increasing, we can utilize this for power generation by means of train track power generation. It has advantage that it does not utilize any external source. As the conventional sources are depleting very fast, then it's time to think of alternatives. We got to save the power gained from the conventional sources for efficient use. So this idea not only provides alternative but also adds to the economy of the country. A properly designed mechanical based electrical generation system has the potential to power major railroad equipment and infrastructure, representing a safety benefit to areas lacking electrical infrastructure. The listed system is non-conventional and the way of power generation technique is also ecofriendly. It has advantage that it does not utilize any external source. 
Vol. 6, No. 7, 2021, PP. 24 -27

\section{International Journal of Innovations in Engineering and Science, www.ijies.net}

\section{REFERENCES}

[1] MingyuanGao, Chengguang Su, Ed., Harvesting thermoelectric energy from railway track,2019 Elsevier Ltd.

[2] Prof S M Hatturkar, Electric Power Generation Using Railway Track, International Journal for Research in Applied Science \& Engineering Technology, Volume 5 Issue IX, September 2017.

[3] Prof. Jag dish Chahande, Bhakti S.Shirke, Ed., Electricity Generation using Railway Tracks, GRD Journals- Global Research and Development Journal for Engineering ,Volume 2 ,Issue 5, April 2017.

[4] Y. Lethwala, Rishabh Jain, AmanAkotkar., Generation of Electrical Energy from Railway Track, SSRG International Journal of Mechanical Engineering (SSRG IJME) - Volume 5 Issue 10-October 2018.
[5] Rajesh V. Kale, Sanjay D. Pohekar, Electricity demandandsupplyscenariosforMaharashtra(India)for 2030:Anapplicationoflongrangeenergyalternativesplannin g, 0301-42152014 Elsevier Ltd.

[6] D. Kostovasilis, D.J. Thompson, M.F.M. Hussein, A semianalytical beam model for the vibration of railway tracks, 0022-460X/\& 2017 Elsevier Ltd.

[7] Loganathan $M$, Prabhakaran $V$ Ed., POWER GENERATION FROM TRAIN TRACK, International Journal of Scientific \& Engineering Research Volume 8, Issue 6, June-2017.

[8] Kafi Mohammad Ullah, K. M. Ahsan-uz-Zaman, Electrical Power Generation Through Speed Breaker, 9th International Conference on Electrical and Computer Engineering 20-22 December, 2016, Dhaka, Bangladesh.

[9] John J. Wang, G.P. Penamalli, and Lei Zuo, Electromagnetic Energy Harvesting from Train Induced Railway Track Vibrations, 2012 IEEE. [10] Design of machine elements, Author- V.B. Bhandar 